\title{
Common bile duct stones and their management
}

\author{
A. Dharmapala \\ Department of Surgery, Faculty of Medicine, University of Peradeniya, Sri Lanka
}

Key words: Common bile duct; stones; jaundice; ERCP

\section{Introduction}

\section{Primary and secondary gall stones}

Common bile duct (CBD) stones cause significant morbidity to the patient by causing obstructive jaundice, cholangitis and pancreatitis. The stones which develop in the CBD itself are known as primary biliary stones and are frequently observed in South East Asian countries. This is mainly due to parasitic infestation by liver flukes (Opisthorchis veverrini, Clonorchis sinensis). The pathogenesis is not directly related to the parasite itself but is due to the combination of stasis of bile and subclinical infection that occurs in the bile that results in stone formation. The infecting organisms are mainly Escherichia coli, Bacteroides and clostridium species which breakdown the conjugated bilirubin into unconjugated bilirubin due to the action of Bglucuronidase and furthermore, the bacteria secrete phospholipase A which produces palmitic and stearic acids. The acid hydrolases break down the conjugated bile acids into unconjugated bile acids. These chemical compounds form insoluble complexes with calcium thus forming brown pigment stones. This is quite apparent when the other conditions that lead to formation of primary biliary stones are considered, where its pathology results in bile stasis. This is seen in conditions like choledocal cysts, biliary strictures (sclerosing cholangitis, benign and malignant strictures) hepaticojejunostomies and foreign bodies ( retained $\mathrm{T}$ tubes, parasites, sutures and blocked stents).

The common bile duct stones seen in the western world are usually migrated stones from the gall bladder. These are known as secondary stones. About $10 \%-15 \%$ of the patients who undergo cholecystectomy will have gall Correspondence: A.Dharmapala

E-mail: arindad@gmail.com stones in the common hepatic ducts, but only $2 / 3$ will give rise to symptoms [2]. These CBD stones should be treated even if these are asymptomatic [3]. Since the diameter of the cystic duct is about $2-3 \mathrm{~mm}$, the stones which can pass through the duct will be very small. These migrated stones or gravel cannot naturally obstruct the common bile duct.

\section{Complications}

Even though these stones are small, they are capable of blocking the ampulla of Vater transiently which may result in causing gall stone pancreatitis. In addition, these stones can give rise to deranged liver enzymes or cause cholangitis. This was clearly demonstrated by a study where small gall stones were detected in faeces of about $90 \%$ of the patients who had gall stone pancreatitis [4]. This shows that transient obstruction and passage of gall stones can cause pancreatitis.

These small stones are unlikely to cause obstructive jaundice. The secondary CBD stones that cause obstructive jaundice are usually large stones. This scenario is not possible with a normal caliber cystic duct (2-3mm). On the other hand, there are short and broad cystic ducts in some patients which may allow migration of bigger stones into the $\mathrm{CBD}$ that might lead to obstruction.

The other instance where stones migrate into the $\mathrm{CBD}$ is through a fistulation between the gall bladder and the CBD. Fistulation usually takes place when a gall stone has impacted in the Hartmann's pouch for a long time. This will result in chronic inflammation and subsequently lead to fistulation between the gall bladder and CBD. This will allow larger stones to pass into the CBD. This is also known as Mirizzi syndrome. There are 4 types of Mirizzi syndrome. In Type 1 there is only external compression of the bile duct. In Types II and III there is fistulation between the gall bladder and hepatic ducts. There is complete destruction of the duct 
observed in Type IV [5]. Mirizzi syndrome is seen in $0.1-0.7 \%$ patients with symptomatic gall stone disease $[6,7]$.

\section{Predictors/Indicators of CBD obstruction}

CBD stones are suspected preoperatively if there is a history of jaundice, pancreatitis, cholangitis, and elevated bilirubin levels or raised liver enzymes (alkaline phosphatase). A dilated biliary duct system on imaging is a strong indicator of CBD obstruction. Trans abdominal ultrasonagraphy is a good initial investigation in picking up gall stones in the gall bladder but it is not the ideal imaging modality to look at the CBD. The sensitivity is around $95 \%$ in picking up stones in the gall bladder, as opposed to poor pick up rate of detecting stones in the CBD where it is around 30\%, although the specificity is $100 \%[8,9]$. Multivariate logistic regression analysis on significant predictors have shown that, if cholangitis [odds ratio (OR): 10.5], a dilated $\mathrm{CBD}$ with evidence of stones in the gall bladder on ultrasound scan (OR: 7.4), elevated aspartate transaminase levels (OR: 2.9), and conjugated bilirubinaemia (OR: 5.3) were considered together, the likelihood of having stones in the duct is about $99 \%$. Without any of these predictors, the likelihood drops to around $7 \%$ [10]. A prospective study of 1000 laparoscopic cholecystectomies showed that $10 \%$ of the patients had diagnosed to have CBD stones on per operative cholangiography where the other parameters were normal. This study also showed that jaundice, cholangitis, raised alkaline phosphatase and dilated CBD were significant predictors of CBD stones [11].

\section{Investigations of CBD stones}

If there is unequivocal evidence of gall stones in the CBD, the preferred method is to undergo ERCP. This has a success rate of $70-90 \%$ as this is a diagnostic as well as therapeutic option [12]. There is a false positivity of around $40-60 \%$ at ERCP. This puts patients through an unnecessary investigation. The Diagnostic ERCP has a morbidity of 5-6 \% and mortality of 0.1$0.89 \%$, Therefore before embarking on this invasive procedure as a diagnostic tool there should be clear indications and should be used as the last investigative procedure to visualize the CBD [13]. Of all the complications in ERCP, ERCP related pancreatitis is the leading cause for morbidity and mortality.
In situations where the diagnosis of $\mathrm{CBD}$ stones is inconclusive, MRCP is a much safer and reliable option. This has a very good sensitivity and specificity of around $90 \%[14,15]$. Contrast CT scanning is also an option in delineating common bile duct stones as this is available in most hospitals, even in emergency settings. This has a sensitivity of $65-93 \%$ and specificity of $84-$ $100 \%$ which is far superior to transabdomonal ultrasonography $[16,17]$.

Endoscopic ultrasonography scan is also gaining popularity. This is also valuable in excluding other pathologies in lower CBD. This also has a sensitivity and specificity similar to MRCP. Meta analyses have had shown a pooled sensitivity of $94 \%$ with specificity of $95 \%$ for detecting stones in the CBD with EUS [18]. Some studies show that it is better than MRCP in detecting small stones less than $5 \mathrm{~mm}$ in diameter with sensitivities of $100 \%[19,20]$. Also, EUS can prevent about $30 \%$ of unnecessary ERCP [21].

In situations where there is a history to suggest CBD stones, such as obstructive jaundice, cholangitis, acute pancreatitis, elevated liver enzymes especially alkaline phosphatase, but no definitive findings just prior to cholecystectomy, the CBD should be imaged with a sensitive imaging modality like MRCP, EUS or CT scan or else during the surgery one should at least perform intraoperative cholangiography. ERCP is better avoided in situations like this to prevent unnecessary mortality and morbidity. The same principle can be applied to patients with a moderate risk of CBD stones i.e. patients who have had deranged liver enzymes with normal caliber CBD. If stones are detected during surgery, one could complete the procedure and later perform ERCP at the same admission or had explore the CBD concurrently [22].

\section{Treatment options}

\section{Endoscopic techniques}

ERCP is becoming the preferred choice in dealing with CBD stones. A nation-wide study carried out in Sweden showed that the use of laparoscopic or open choledochotomy (CBD exploration) had dropped from 19.4 to 5.2 and ERCP had gone up 5.1 to 26.4 per 100,000 population per year. What this change has done is that there were more readmissions of patients with 
biliary and pancreatic complications due to the paradigm shift from choledochotomy to ERCP [23]. This is due to the fact that after sphincterotomy and stone removal from the $\mathrm{CBD}$, the patients are discharged and the cholecystectomy is usually scheduled for a later date. During this period patients present back to the hospital with the above mentioned complications. But this was not the case earlier, in patients with CBD stones and gall stones where surgery was done to remove $\mathrm{CBD}$ stones and the gallbladder in the same setting.

\section{Stone extraction}

In most instances, a sphincterotomy is done before the extraction of stones when it is done endoscopically. But if there is a coagulopathy, a sphincterotomy is not possible as this will lead to bleeding. Instead, endoscopists resort to balloon dilatation prior to extraction or a stent is placed as a temporary measure. The problem with balloon dilatation is that it carries a risk of post ERCP pancreatitis, which is significantly higher than with sphincterotomy. A US multicenter study showed that the pancreatitis rate was $15.4 \%$ in the balloon dilated group compared to $0.8 \%$ in the sphincterotomy group. This difference was significant. Some other studies also have shown similar results thus favouring sphincterotomy prior to stone removal $[24,25,26]$.

For stone removal, the dormia basket and the balloon are being frequently used. The sphincterotomy makes it easier for the extraction.

\section{Large Stones}

Larger CBD stones pose a challenge to the endoscopist. A larger sphincterotomy is always advisable, but intraductal mechanical lithotripters and laser lithotripters are used to break the stones. These are successful most of the time [27]. The success rate varies in different studies, ranging from $79 \%$ to $95 \%[27,28]$. If such devices are not available, it is advisable to carry out open CBD explorations. Stones of $1.5 \mathrm{~cm}$ are considered to be large stones in most studies but it has been shown that size of the stone was not a predictor for the failure of the endoscopic procedure. However impaction of the stone in the CBD and the anatomical variations of the $\mathrm{CBD}$ are factors that have led to failures [28].
Comparative studies on sphincterotomies and large balloon dilatations vs usage of mechanical lithotripters in extracting larger stones have indicated that both procedures show equal success rates with a marginally higher incidence of complications in the balloon dilatation group [29].

The use of the spyglass in directly visualizing the CBD when using the laser lithotripter is also being carried out with a few studies documenting the success of this procedure [30].

ERCP and sphincterotomy to extract stones in the younger age group poses the question of long term complications due to enteric reflux. Studies showed that complication rates were $11-19 \%$, the majority of which were due to recurrent stone formation [31]. There were no reported cases of cholangio carcinoma on long term follow up. Almost all these complications were dealt with endoscopically. Studies have shown that a CBD diameter of more than $1.5 \mathrm{~cm}$, brown pigment stones and prepapillary diverticula are risk factors for the development of long term complications [31,32, 33].

\section{Exploration of CBD}

Exploration of the CBD can be done laparoscopically or as an open procedure. Laparoscopic CBD exploration should be considered in situations where there is a dilated duct. This has to be done by an experienced surgeon and is not a task for a novice. There are two methods of exploring the CBD. One is through the cystic duct (trans cystic) when the duct is short and wide and the other through a choledochotomy on the anterior wall. These techniques have a complication rate of 2$17 \%$ and a mortality rate of $1-5 \%$ which are similar to those of ERCP [34].

Open exploration of the $\mathrm{CBD}$ is now becoming confined to situations where laparotomy is necessary for other reasons. After exploration of the CBD, a completion choledocoscopic examination or a completion cholangiogram should be considered to avoid leaving behind stones in the CBD. These are known as missed stones. The residual stones detected after routine CBD exploration with completion cholangiogram are in the range of $6-11 \%[4,35]$.

After the exploration, the CBD is usually closed over a $\mathrm{T}$ tube. The $\mathrm{T}$ tube should be brought out from the closest 
possible place in the anterior abdominal wall, expecting a short tract. This is due to the fact that if some intervention is needed later, the tract can be used as an access route. This also facilitates easy removal of the $\mathrm{T}$ tube. After removal of the $T$ tube there will be leakage of bile for a short period of time but this dries off quickly. The risk of peritoneal contamination after removal is minimal and is extremely rare [36].

Performing a $\mathrm{T}$ tube cholangiogram before removal should be considered if a completion cholangiogram was not carried out during surgery. If missed stones are detected by a $\mathrm{T}$ tube cholangiogram, the $\mathrm{T}$ tube can be used to flush the CBD. There should not be excessive pressure when flushing as it can lead to reflux of bile into the circulation. The drip should be kept at a height of 1 meter and free flow enabled. If this fails to flush away the stones, the T tube is left in situ for $3-4$ weeks for the maturation of the tract. Later, with the aid of a choledochoscope stones can be extracted through the tract.

Cochrane analyses of trials comparing the $\mathrm{T}$ tube drainage vs primary closure of the CBD after laparoscopic CBD exploration have shown that there is no difference in morbidity and mortality rates and recommend closing the $\mathrm{CBD}$ primarily. The $\mathrm{T}$ tube drainage group had a longer hospital stay when compared to the other group $[37,38]$. The same group has shown similar results in another meta-analyses where it was reported that even after open CBD exploration, one can close the CBD primarily without a $\mathrm{T}$ tube [39]. Another study has shown choledochotomy closure over a stent results in a shorter postoperative stay and an earlier return to normal activity compared with closure over a T-tube without any increase in morbidity [40]. These studies and systematic reviews show that it is safer to close CBD primarily rather than using a $\mathrm{T}$ tube drainage procedure. This has to be considered in individual cases, ensuring that there are no residual stones or strictures at the ampulla because this can lead to leakage of bile from the suture line. If there is no back pressure there will be no bile leak from the suture line.

\section{Conclusion}

This article mainly tries to discuss the problems that arise in the management of CBD stones. It is impossible to pick a single best method of management as this depends on the available resources and the skills of the individual surgeon. That would be the best evidence based practice where the safety of the patient becomes the number one priority. It is not an easy task for surgeons to be conversant with every new technique and to keep up with the latest inventions that are brought on every day, especially in biliary tract surgery where the margin for error is minimal, and most of the time there will be no second chance for the surgeon. Therefore this article gives the currently available data on CBD stone management in order to compare and improve on his or her practice.

\section{References}

1. Vítek, L. and M. C. Carey (2012). "New pathophysiological concepts underlying pathogenesis of pigment gallstones." Clinics and research in hepatology and gastroenterology 36(2): 122-129.

2. Williams EJ, Green J, Beckingham I, et al. Guidelines on the management of the common bile duct stones. Gut 5 Mar 2008;57:1004-21.

3. Scientific Committee of the European Association for Endoscopic Surgery (E.A.E.S.) Diagnosis and treatment of common bile duct stones (CBDS): results of a consensus development conference. SurgEndosc. 1998;12:856-864.

4. Rajendra Desai, Bahaman N. Shokouhi . REVIEW ARTICLE Common bile duct stones - their presentation, diagnosis and management. Indian J Surg (September-October 2009) 71:229-237.

5. Csendes A, Diaz JC, Burdiles P, et al. Mirizzi syndrome and cholecystobiliary fistula: a unifying classification. Br J Surg 1989;76(11):1139-43.

6. Frilling A, Li J, Weber F, et al. Major bile duct injuries after laparoscopic cholecystectomy: a tertiary centre experience. J GastrointestSurg 2004; 8(6):679-85.

7. MacFayden BV Jr, Vecchio R, Ricardo AE, etal.Bile duct injury after laparoscopic cholecystectomy: the United states experience. SurgEndosc 1998;12(4)315-21.

8. Onken JE, Brazer SR, Eisen GM, et al. Predicting the presence of choledocholithiasis in patients with symptomatic cholelithiasis. Am J Gastroenterol 1996;91:762-7.

9. Trondsen E, Edwin B, Reiertsen o, et al. Prediction of 
common bile duct stonesprior to cholecystectomy: a prospective validation of a discriminant analysis function. Arch Surg 1998;133:162-6.

10. Alponat A, Kum CK, Rajnakova A, Koh BC, Goh PM. Predictive factors for synchronous common bile duct stones in patients with cholelithiasis. SurgEndosc. 1997 Sep; 11(9):928-32.

11. Sheen AJ, Asthana S, Al-Mukhtar A, Attia M, Toogood GJ. Preoperative determinants of common bile duct stones during laparoscopic cholecystectomy. Int J ClinPract. 2008 Nov;62(11):1715-9.

12. Petelin JB, Pruett CS. Common bile duct stones. In Cameron JL, editor. Current Surgical therapy. 8th edition. Philadelphia:Elsevier Mosby; 2004. P.392-9.

13. EC KaltenthalerSJ Walters, , J Chilcott. MRCP compared to diagnostic ERCP for diagnosis when biliary obstruction is suspected: a systematic review. BMC medical ..., 2006 biomedcentral.com

14. Soto JA, Alvarez O, Munera F, et al. Diagnosing bile duct stones: Comparison of unenhanced helical CT,oral contrast enhanced CT cholangiography and M R cholangiography.AJR Am JRoentgenol 2000;175:1127-34.

15. Dermatines N, Eisner L,Schnabel K, et al. Evaluation of magnetic resonance cholangiography in the management of biloe duct stones. Arch Sug 2000;135:148-52.

16. Ishikawa, M., Y. Tagami, et al. (2000). "Can threedimensional helical CT cholangiography before laparoscopic cholecystectomy be a substitute study for endoscopic retrograde cholangiography?" Surgical Laparoscopy Endoscopy \& Percutaneous Techniques 10(6): 351-356.

17.Polkowski M, Palucki J, Regula J, et al. Helical computed tomographycholangiography vs endosonography for suspected bile duct stones:Prospective blided study in no jaundice patients.GUT1999;45:744-9.

18. Tse, F., L. Liu, et al. (2008). "EUS: a meta-analysis of test performance in suspected choledocholithiasis." Gastrointest Endosc 67(2): 235-244.

19. de Lédinghen, V., R. Lecesne, et al. (1999). "Diagnosis of choledocholithiasis: EUS or magnetic resonance cholangiography? A prospective controlled study." Gastrointest Endosc 49(1): 26-31.
20. Kondo, S., H. Isayama, et al. (2005). "Detection of common bile duct stones: comparison between endoscopic ultrasonography, magnetic resonance cholangiography, and helical-computed-tomographic cholangiography." Eur J Radiol 54(2): 271-275.

21. Ang, T., E. Teo, et al. (2007). "Endosonography-vs. endoscopic retrograde cholangiopancreatography-based strategies in the evaluation of suspected common bile duct stones in patients with normal transabdominal imaging." Alimentary pharmacology \& therapeutics 26(8): 1163-1170.

22. Zang JF, Zhang C, Gao JY.Endoscopic retrograde cholangiopancreatography and laparoscopic cholecystectomy during the same session: Feasibility and safety.World J Gastroenterol. 2013 Sep 28; 19(36):6093-7.

23. Sandzén, B., M. M. Haapamäki, et al. (2012). "Treatment of common bile duct stones in Sweden 1989-2006: an observational nationwide study of a paradigm shift." World J Surg 36(9): 2146-2153.

24. Baron, T. H. and G. C. Harewood (2004). "Endoscopic balloon dilation of the biliary sphincter compared to endoscopic biliary sphincterotomy for removal of common bile duct stones during ERCP: a metaanalysis of randomized, controlled trials." Am J Gastroenterol 99(8): 1455-1460.

25. DiSario, J. A., M. L. Freeman, et al. (2004). "Endoscopic balloon dilation compared with sphincterotomy for extraction of bile duct stones." Gastroenterology 127(5): 1291-1299.

26. Tsujino, T., T. Kawabe, et al. (2007). "Endoscopic papillary balloon dilation for bile duct stone: immediate and long-term outcomes in 1000 patients." Clinical Gastroenterology and Hepatology 5(1): 130-137.

27. Hintze, R. E., A. Adler, et al. (1995). "Outcome of mechanical lithotripsy of bile duct stones in an unselected series of 704 patients." Hepatogastroenterology 43(9): 473 476.

28. Garg, P. K., R. K. Tandon, et al. (2004). "Predictors of unsuccessful mechanical lithotripsy and endoscopic clearance of large bile duct stones." Gastrointest Endosc 59(6): 601-605.

29. Stefanidis, G., N. Viazis, et al. (2011). "Large balloon dilation vs. mechanical lithotripsy for the management of large bile duct stones: a prospective randomized study." Am J Gastroenterol 106(2): 278-285. 
30. Chen, Y. K. and D. K. Pleskow (2007). "SpyGlass singleoperator peroral cholangiopancreatoscopy system for the diagnosis and therapy of bile-duct disorders: a clinical feasibility study (with video)." Gastrointest Endosc 65(6): 832-841.

31. Bergman, J. J., S. van der Mey, et al. (1996). "Long-term follow-up after endoscopic sphincterotomy for bile duct stones in patients younger than 60 years of age." Gastrointest Endosc 44(6): 643-649.

32. Pereira-Lima, J. C., R. Jakobs, et al. (1998). "Long-term results (7 to 10 years) of endoscopic papillotomy for choledocholithiasis. Multivariate analysis of prognostic factors for the recurrence of biliary symptoms." Gastrointest Endosc 48(5): 457-464.

33. Sugiyama, M. and Y. Atomi (2002). "Risk factors predictive of late complications after endoscopic sphincterotomy for bile duct stones: long-term (more than 10 years) follow-up study." Am J Gastroenterol 97(11): 2763 2767.

34. Martin DJ, Vernon DR, Toouli J. Surgical versus endoscopic treatment of bile duct stones. Cochrane Data base Syst Rev 2006;(2).

35. Targarona EM, Bendahan GE (2004) Management of common bile duct stones: controversies and future perspectives. HPB 6(3):140-143.

36. AhmedM , Diggory RT.Case-based review: bile peritonitis after T-tube removal. Ann R CollSurg Engl. 2013 Sep;95(6):383-5.

37. Gurusamy KS, Koti R, Davidson BR. T-tube drainage versus primary closure after laparoscopic common bile duct exploration. Cochrane Database Syst Rev. 2013 Jun 21;6:CD005641.

38. Yin Z, Xu K, Sun J, Zhang J, Xiao Z, Wang J, Niu H, Zhao $\mathrm{Q}$, Lin $\mathrm{S}, \mathrm{Li} \mathrm{Y}$. Is the end of the T-tubedrainage era in laparoscopic choledochotomy for common bile duct stones is coming? A systematic review and meta-analysis. Ann Surg. 2013 Jan;257(1):54-66.

39. Gurusamy KS, Koti R, Davidson BR. T-tubedrainage versus primary closure after open common bile duct exploration. Cochrane Database Syst Rev. 2013 Jun 21;6:CD005640. doi: 10.1002/14651858.CD005640.pub3.

40. Mangla V, Chander J, Vindal A, Lal P, Ramteke VK. A randomized trial comparing the use of endobiliary stent and $\mathrm{T}$ tube for biliary decompression after laparoscopic common bile duct exploration. SurgLaparoscEndoscPercutan Tech. 2012 Aug; 22(4):345-8. 